\title{
COMPARING ECCENTRICITY-BASED GRAPH INVARIANTS
}

\author{
Hongbo Hua, Hongzhuan Wang \\ Faculty of Mathematics and Physics \\ Huaiyin Institute of Technology \\ Huai'an, Jiangsu 223003, P.R. China \\ e-mail: hongbo_hua@163.com \\ wanghz412@163.com \\ AND \\ Ivan Gutman \\ Faculty of Science \\ University of Kragujevac \\ 34000 Kragujevac, Serbia \\ e-mail: gutman@kg.ac.rs
}

\begin{abstract}
The first and second Zagreb eccentricity indices $\left(E M_{1}\right.$ and $\left.E M_{2}\right)$, the eccentric distance sum (EDS), and the connective eccentricity index (CEI) are all recently conceived eccentricity-based graph invariants, some of which found applications in chemistry. We prove that EDS $\geq E M_{1}$ for any connected graph, whereas EDS $>E M_{2}$ for trees. Moreover, in the case of trees, $E M_{1} \geq \mathrm{CEI}$, whereas $E M_{2}>\mathrm{CEI}$ for trees with at least three vertices. In addition, we compare EDS with $E M_{2}$, and compare $E M_{1}, E M_{2}$ with CEI for general connected graphs under some restricted conditions.
\end{abstract}

Keywords: eccentricity (of vertex), Zagreb eccentricity index, eccentric distance sum, connective eccentricity index.

2010 Mathematics Subject Classification: 05C35, 05C12.

\section{REFERENCES}

[1] Y. Alizadeh and S. Klavžar, Complexity of topological indices: The case of connective eccentric index, MATCH Commun. Math. Comput. Chem. 76 (2016) 659-667. 
[2] M. Aouchiche and P. Hansen, Proximity and remoteness in graphs: results and conjectures, Networks 58 (2011) 95-102.

doi:10.1002/net.20450

[3] M. Azari and A. Iranmanesh, Computing the eccentric-distance sum for graph operations, Discrete Appl. Math. 161 (2013) 2827-2840. doi:10.1016/j.dam.2013.06.003

[4] J.A. Bondy and U.S.R. Murty, Graph Theory (Springer, New York, 2008).

[5] B. Borovićanin, K.C. Das, B. Furtula and I. Gutman, Bounds for Zagreb indices, MATCH Commun. Math. Comput. Chem. 78 (2017) 17-100.

[6] K.C. Das, Some properties of the Zagreb eccentricity indices, Ars Math. Contemp. 6 (2013) 117-125. doi:10.26493/1855-3974.237.48a

[7] K.C. Das, Comparison between Zagreb eccentricity indices and the eccentric connectivity index, the second geometric-arithmetic index and the Graovac-Ghorbani index, Croat. Chem. Acta 89 (2016) 505-510. doi:10.5562/cca3007

[8] K.C. Das, I. Gutman and M.J. Nadjafi-Arani, Relations between distance-based and degree-based topological indices, Appl. Math. Comput. 270 (2015) 142-147. doi:10.1016/j.amc.2015.08.061

[9] K.C. Das and M.J. Nadjafi-Arani, Comparison between the Szeged index and the eccentric connectivity index, Discrete Appl. Math. 186 (2015) 74-86. doi:10.1016/j.dam.2015.01.011

[10] A. Dobrynin, R. Entringer and I. Gutman, Wiener index of trees: theory and applications, Acta Appl. Math. 66 (2001) 211-249. doi:10.1023/A:1010767517079

[11] S. Fajtlowicz and W.A. Waller, On two conjectures of GRAFFITI II, Congr. Numer. 60 (1987) 187-197.

[12] X. Geng, S. Li and M. Zhang, Extremal values on the eccentric distance sum of trees, Discrete Appl. Math. 161 (2013) 2427-2439.

doi:10.1016/j.dam.2013.05.023

[13] M. Ghorbani and M.A. Hosseinzadeh, A new version of Zagreb indices, Filomat 26 (2012) 93-100. doi:10.2298/FIL1201093G

[14] S. Gupta, M. Singh and A.K. Madan, Connective eccentricity index: a novel topological descriptor for predicting biological activity, J. Mol. Graph. Model. 18 (2000) $18-25$. doi:10.1016/S1093-3263(00)00027-9

[15] S. Gupta, M. Singh and A.K. Madan, Eccentric distance sum: A novel graph invariant for predicting biological and physical properties, J. Math. Anal. Appl. 275 (2002) 386-401. doi:10.1016/S0022-247X(02)00373-6 
[16] I. Gutman, B. Ruščić, N. Trinajstić and C.F. Wilcox, Graph theory and molecular orbitals. XII. Acyclic polyenes, J. Chem. Phys. 62 (1975) 3399-3405. doi:10.1063/1.430994

[17] I. Gutman and N. Trinajstić, Graph theory and molecular orbitals. Total $\pi$-electron energy of alternant hydrocarbons, Chem. Phys. Lett. 17 (1972) 535-538. doi:10.1016/0009-2614(72)85099-1

[18] H. Hua, Y. Chen and K.C. Das, The difference between remoteness and radius of a graph, Discrete Appl. Math. 187 (2015) 103-110. doi:10.1016/j.dam.2015.02.007

[19] H. Hua and K.C. Das, The relationship between the eccentric connectivity index and Zagreb indices, Discrete Appl. Math. 161 (2013) 2480-2491. doi:10.1016/j.dam.2013.05.034

[20] H. Hua and K.C. Das, Proof of conjectures on remoteness and proximity in graphs, Discrete Appl. Math. 171 (2014) 72-80. doi:10.1016/j.dam.2014.02.011

[21] H. Hua, K. Xu and S. Wen, A short and unified proof of Yu et al.'s two results on the eccentric distance sum, J. Math. Anal. Appl. 382 (2011) 364-366. doi:10.1016/j.jmaa.2011.04.054

[22] H. Hua, S. Zhang and K. Xu, Further results on the eccentric distance sum, Discrete Appl. Math. 160 (2012) 170-180. doi:10.1016/j.dam.2011.10.002

[23] A. Ilić, G. Yu and L. Feng, On the eccentric distance sum of graphs, J. Math. Anal. Appl. 381 (2011) 590-600. doi:10.1016/j.jmaa.2011.02.086

[24] S. Li and Y. Wu, On the extreme eccentric distance sum of graphs with some given parameters, Discrete Appl. Math. 206 (2016) 90-99. doi:10.1016/j.dam.2016.01.027

[25] Z. Luo and J. Wu, Zagreb eccentricity indices of the generalized hierarchical product graphs and their applications, J. Appl. Math. 1 (2014) 1-8. doi:10.1155/2014/241712

[26] V. Mukungunugwa and S. Mukwembi, On eccentric distance sum and minimum degree, Discrete Appl. Math. 175 (2014) 55-61. doi:10.1016/j.dam.2014.05.019

[27] S. Nikolić, G. Kovačević, A. Miličević and N. Trinajstić, The Zagreb indices 30 years after, Croat. Chem. Acta 76 (2003) 113-124.

[28] X. Qi and Z. Du, On Zagreb eccentricity indices of trees, MATCH Commun. Math. Comput. Chem. 78 (2017) 241-256.

[29] X. Qi, B. Zhou and J. Li, Zagreb eccentricity indices of unicyclic graphs, Discrete Appl. Math. 233 (2017) 166-174. doi:10.1016/j.dam.2017.08.001 
[30] D. Vukičević and A. Graovac, Note on the comparison of the first and second normalized Zagreb eccentricity indices, Acta Chim. Sloven. 57 (2010) 524-528.

[31] R. Xing, B. Zhou and N. Trinajstić, On Zagreb eccentricity indices, Croat. Chem. Acta 84 (2011) 493-497. doi:10.5562/cca1801

[32] G. Yu and L. Feng, On the connective eccentricity index of graphs, MATCH Commun. Math. Comput. Chem. 69 (2013) 611-628.

[33] G. Yu, L. Feng and A. Ilić, On the eccentric distance sum of trees and unicyclic graphs, J. Math. Anal. Appl. 375 (2011) 99-107. doi:10.1016/j.jmaa.2010.08.054

[34] G. Yu, H. Qu, L. Tang and L. Feng, On the connective eccentricity index of trees and unicyclic graphs with given diameter, J. Math. Anal. Appl. 420 (2014) 1776-1786. doi:10.1016/j.jmaa.2014.06.050

[35] H. Zhang, S. Li and B. Xu Extremal graphs of given parameters with respect to the eccentricity distance sum and the eccentric connectivity index, Discrete Appl. Math. 254 (2019) 204-221.

doi:10.1016/j.dam.2018.07.013

Received 26 January 2018

Accepted 18 August 2018 